\title{
NUMERICAL ANALYSIS OF THE EFFECTS OF THE BENDING STIFFNESS OF THE CABLE AND THE MASS OF STRUCTURAL MEMBERS ON FREE VIBRATIONS OF SUSPENSION BRIDGES
}

\author{
Tatjana GRIGORJEVA, Zenonas KAMAITIS \\ Vilnius Gediminas Technical University, Sauletekio al. 11, LT-10223 Vilnius, Lithuania
}

Received 17 Oct 2014; accepted 22 Apr 2015

\begin{abstract}
The article determines natural frequencies of vibration and the corresponding mode shapes of a suspension bridge with the varying bending stiffness of cables and examines variations that occur in these characteristics with respect to parametric changes in the bridge. A single span suspension steel footbridge with flexible cables has been selected as an initial model used for studying the dynamic characteristics of a suspension system. With the help of the finite elements (FE) method, parameter studies of the bridge model are presented in which vibration characteristics are studied as a function of structural and material parameters such as the flexural stiffness of the cable and the mass density of structural components. It has been generally found that the bending stiffness of the main cable contributes to a considerable effect on natural frequencies for this type of the suspension system. A simplified expression of predicting natural bending frequencies of the suspension bridge taking into account the bending stiffness of the cable has been developed for the application as the first step in the design process.
\end{abstract}

Keywords: suspension bridges, bending stiffness of the cable, mass of structural members, free vibrations, frequencies and mode shapes, FE analysis.

\section{Introduction}

Cable supported bridges typically of long spans are the most important and attractive structures possessing a number of technical, economical and aesthetic advantages. Increased deformability can be considered as the basic disadvantage of suspension systems. These structures are particularly susceptible to large vibrations induced by traffic and wind actions sometimes leading to the problems of serviceability and safety (e.g. Barelli et al. 2006; Caetano 2007; Gimsing, Georgakis 2011; Irvin et al. 2005). In general, the deformability of a suspension system depends on the kinematic character of the displacements of a flexible suspension cable. As regards the analysis of suspension bridges, the main cables are generally assumed to have no bending stiffness and to be subject to axial tension only.

There are different strategies for reducing the deformability of cable suspended structures (Faridani, Barghian 2012; Tabatabai, Mehrabi 2000). The commonly adopted structural measures consist of local or total structural modifications by changing mainly the stiffness or mass of a structure as well as through the installation of tuned mass dampers (Bruno et al. 2012; Carpineto et al.2010; Phongkumsing et al. 2001).
As shown in our previous investigations, a possible strategy for the modification of the structural stiffness of the suspension system is the variation of the bending stiffness of the main cable (Grigorjeva et al. 2004, 2008). To account for the effect of the bending stiffness of the cable, analytical methods have been proposed (Grigorjeva et al. 2010; Juozapaitis et al. 2010, 2013). It has been shown that, compared with the common types of steel suspension bridges, the systems with cables of finite bending stiffness provide certain advantages such as a considerable reduction in system deformability under the action of symmetrical and asymmetrical static loading, simpler detailing and corrosion protection and saving materials. So far, according to the authors, investigation into the dynamic global response of the suspension bridges with account for the effect of the bending stiffness of the cables has not been carried out.

Many researchers have investigated the dynamic characteristics of cable supported bridges, including the effect of the bending stiffness of the cable and considering the cables isolated from the bridge structure (e.g. Ni et al. 2002; Takahashi, Chen 2006; Ricciardi, Saitta 2008; Treyssede 2010; Sousa et al.2011; El Ouni, Kahla 2012). The obtained results show that the bending stiff-

Corresponding author: Tatjana Grigorjeva

E-mail: tatjana.grigorjeva@vgtu.lt 
ness of the cable contributes to a considerable influence on its natural frequencies, particularly of higher frequency modes. Some authors (e.g. Tabatabai, Mehrabi 2000; Ni et al. 2002; Caetano 2007) use the nondimensional parameter of the bending stiffness of the cable $\xi=\sqrt{H L^{2} / E I}$, where $H$ is a horizontal component of cable tension, $L$ is cable length and $E I$ is the bending stiffness of the cable. The natural frequencies of cable vibration can be expressed, for example (Geier et al. 2006), as $f_{k}=f_{k s} \times \alpha_{k}$, where $f_{k s}$ is the frequency of the cable at $E I=0$; bending stiffness parameter $\alpha_{k}=1+2 / \xi+\left(4+k^{2} \pi^{2} / 2\right) 1 / \xi^{2} ; k$ is mode number. In case $\xi \geq 100$, which very frequently occurs in practice, the effect of the bending stiffness o the cable is negligible (Caetano 2007). Although, as regards very long span suspension bridges having large diameter wire cables, the effect of their bending stiffness should be taken into account for an accurate evaluation of the modal properties of freely supported cables (e.g. Ni et al. 2002; Ricciardi, Saitta 2008). As for isolated cables, it should be stressed that there are many reported cases when a strong interaction between cables and deck/towers have been observed thus affecting the global dynamic behaviour of bridge structures. Studies on the complex system of a slender suspension bridge with top, bottom and side cables could be also mentioned (Huang et al. 2005). The suspension system having increased top cable dimensions (diameters) approximately up to 2.8 times leads to an increase in free vibration frequencies of the first lowest vertical and torsional-lateral modes by 1.67 and 1.37 times, accordingly. The frequencies of all coupled lateral-torsional modes also rise, but the frequencies of higher coupled torsional-lateral and vertical modes change slightly.

For designing suspension bridges, it is critical to know the natural frequencies of the structure. A number of researchers have developed numerous analytical methods for analysing free vibrations of suspension bridges (e.g. Banerjee 2003; Luco, Turmo 2010; also see the references therein). The analysis and design of suspension bridges with flexible cables are based on the governing equation for motion, which requires a solution to complex differential equations with a different degree of approximations. A more detailed dynamic analysis of cable supported structures can be made using finite-element methods. The finite-element approach eliminates the need to solve transcendental frequency equations providing the capability for deeper dynamic analysis.

The main objective of this study is to investigate the influence of the bending stiffness of the main cables on the free vibration response of suspension bridges. The FE method has been used for simulating their dynamic behaviour. In numerical analysis, the effects of the selfweight of the cable and stiffening girder have been studied. In addition, a simple analytic method for predicting bending natural frequencies of the suspension bridge taking into account the bending stiffness of the cable has been proposed.

\section{Bridge description and the FE model}

The effect of the bending stiffness of the main cable on free vibration characteristics of the suspension bridge has been analysed as an example of the project on the footbridge designed as a suspension steel structure. The elevation layout and cross section of the footbridge are shown in Figure 1.

The footbridge consists of a single span superstructure of $64 \mathrm{~m}$ in length and $4 \mathrm{~m}$ in width, which includes two main suspension cables, suspenders and the stiffening deck girder. The bridge deck consists of longitudinal hollow section steel beams with the stiffened orthotropic steel plate deck, cross girders and a thick polymer wearing surface. For footbridge modelling, the structure has been slightly simplified (Fig. 2). The girder deck and cables are hinged to tower footings and tops respectively. The cables are free to rotate but fixed against translation in any direction at the towers.

The following data have been used in numerical simulations: $L=64.0 \mathrm{~m}$, cable sag $f_{0}=6.5 \mathrm{~m}$, the width of the deck $-4.0 \mathrm{~m}$. Steel suspender rods of $20 \mathrm{~mm}$ in diameter are equally spaced every $3.0 \mathrm{~m}$ and pinned to the main cable and stiffening girder. Their axial stiffness is $E A_{S}=6.6 \times 10^{4} \mathrm{kN}$. In the initial suspension system, flexible wire cables make $0.05 \mathrm{~m}$ in diameter. The rigidity of flexible cables is $E A_{c}=41.2 \times 10^{4} \mathrm{kN}$ and that of stiffening beam $E I_{d x}=10.7 \times 10^{4} \mathrm{kNm}^{2}$ and $E I_{d y}=3870 \times 10^{4} \mathrm{kNm}^{2}$. The dead load of the bridge deck is $10.14 \mathrm{kN} / \mathrm{m}$ and is constant along the span. A horizontal component of cable tension $H=774.8 \mathrm{kN}$.

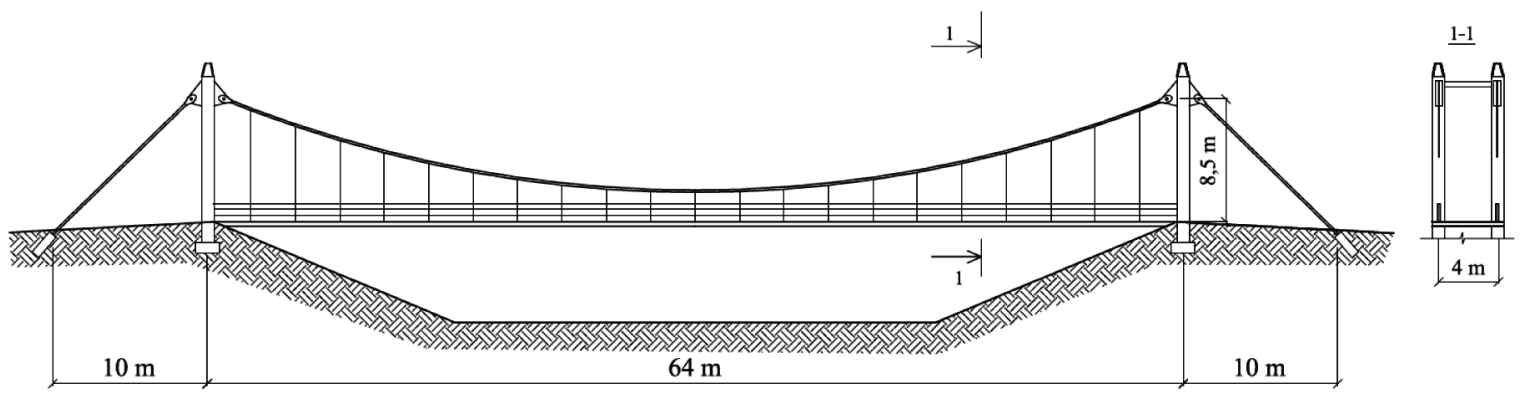

Fig. 1. General layout of a suspension footbridge 


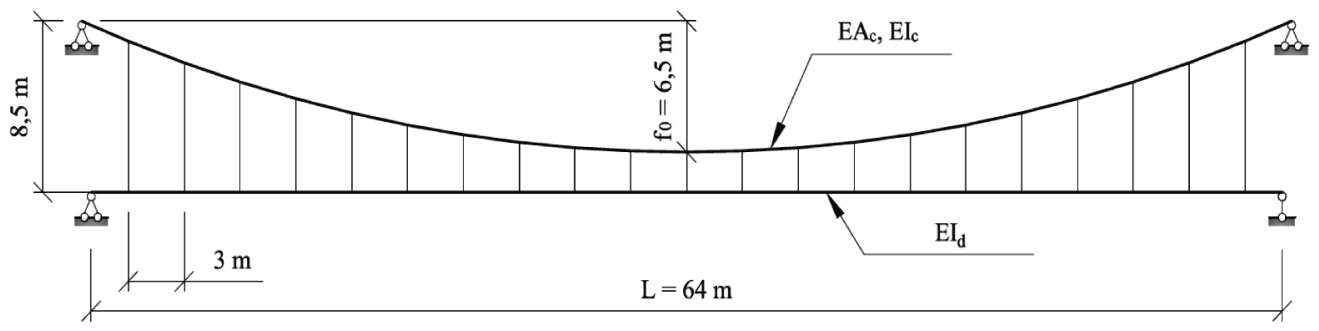

Fig. 2. Model for a single span suspension bridge

The effect of the bending stiffness of the cables on the modal properties of the basic model of the bridge has been studied by varying only the cross section of the cables, and, as a result, the cable of beam bending stiffness parameter $\xi=E I_{c} / E I_{d}=0.2 ; 0.5 ; 1.0 ; 2.0$ and 5.0. This leads to variations in the stiffness and mass properties of the component structure. The main rigid cables are steel members of a tubular cross-section with a varying moment of inertia. It should be mentioned that in long-span suspension bridges, for example, Messina Strait Bridge in Italy, the stiffness of the main cables becomes dominant with respect to that of the deck (Bartoli et al. 2009).

For all structural members, the basic material is steel with $E=210 \mathrm{GPa}, \mu=0.3$ and $\gamma=7850 \mathrm{~kg} / \mathrm{m}^{3}$.

A dynamic as well as static non-linear analysis of the bridge model was carried out using the $3 D F E$ model developed in program package MIDAS Civil, as shown in Figure 3. Elements TRUSS3D were used for representing the flexible cable and suspenders. Beam elements $B E A M 3 D$ were applied for rigid cables and the stiffening girder.

The studies using the developed model consisted of the analysis of its static behavior under the self-weight load followed by the simulation of free dynamic response and the extraction of natural frequencies and corresponding mode shapes of the whole structure.

\section{Static behavior of the model for the bridge}

To investigate the static stiffness of the model for the suspension bridge with the varying bending stiffness of cables, the displacement of the self-weight load of the bridge was calculated using the $3 D F E$ developed model (see Fig. 3).

Figure 4 shows vertical displacements of the stiffening girder under the action of a symmetrical dead load as a function of the bending stiffness parameter $\xi$ of the cable. Vertical displacements of the stiffening girder are

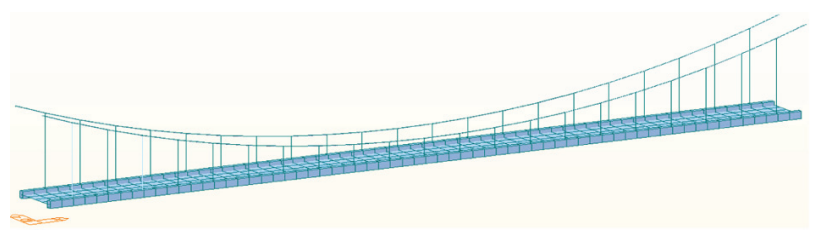

Fig. 3. A finite element space model of the bridge

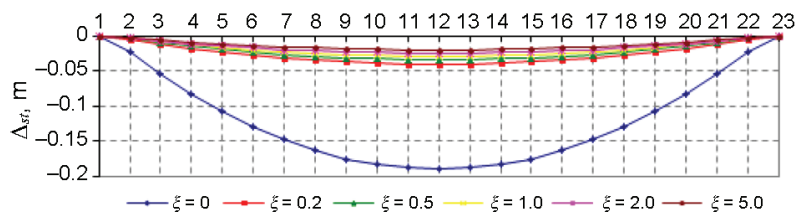

Fig. 4. Curves of a vertical displacement under the self-weight load versus the stiffness parameter $x$ of the cable

reduced due to the participation of the rigid cable as a part of the suspension system. The magnitude of a reduction will depend on the bending stiffness of cables. The main reduction in displacements at mid-span by about $80 \%$ is observed only at the lowest value of the parameter $\xi=0.2$ of cable stiffness. This illustrates that the bending stiffness of the cable has a significant effect on the stiffness of the whole system and thereby inevitable will influence its dynamic behaviour.

Vertical displacements of the bridge at the mid-span obtained from FE analysis have been compared with available analytical formulae suggested in our previous investigations (Grigorjeva et al. 2010).

The vertical deflection of the bridge at mid-span is expressed in the form:

$$
\Delta_{s t}=\frac{0,375 m L^{4}}{16 f_{0}^{2} E A_{c}+28,8 E I_{c}+30 E I_{d}},
$$

where: $m$ is self-weight per unit length of the span, $[\mathrm{kN} / \mathrm{m}] ; f_{0}$ is cable sag, $[\mathrm{m}] ; E A_{c}$ is the axial stiffness of the cable, [kN]; $E I_{c}$ and $E I_{d}$ is the bending stiffness of the cable and deck respectively, $\left[\mathrm{kNm}^{2}\right]$.

Mid-span deflections are given in Figure 5. A comparison shows that vertical displacements at mid-span obtained by numerical simulations are very similar to analytical results (maximum difference is within 5\%).

\section{Modal parameters of the model for the bridge with flexible cables}

Suspension bridges as slender structures having low damping characteristics can exhibit a large number of pure as well as coupled vibration modes. In the initial step, fifty lower natural modes with corresponding natural frequencies in the range of $0-10 \mathrm{~Hz}$ were extracted 


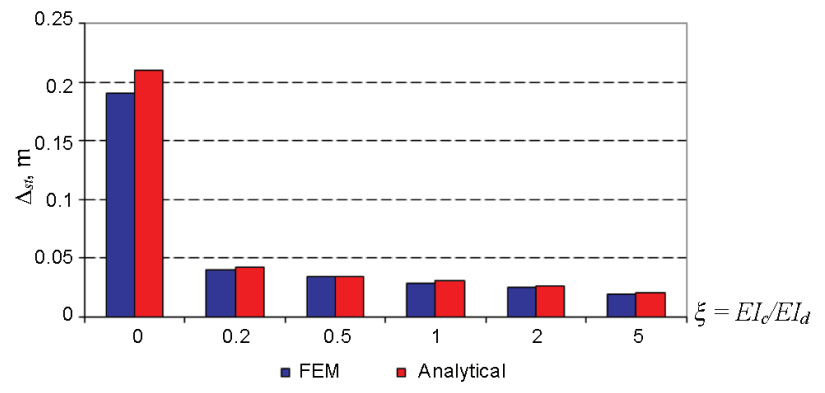

Fig. 5. A comparison of mid-span deflections obtained by FE analysis and analytical formula (1) for different values of the bending stiffness parameter $\xi$ of the cable

Table 1. Computed eigen-frequencies and eigen-modes

\begin{tabular}{l|c|c}
\hline Mode No & Frequency $[\mathrm{Hz}]$ & Character of eigen-mode \\
\hline 1 (V2) & 0.616 & $2^{\text {nd }}$ vertical \\
2 (V3) & 1.128 & $3^{\text {rd }}$ vertical \\
3 (T2-L) & 1.812 & $2^{\text {nd }}$ torsional-lateral \\
$4(\mathrm{~V} 4)$ & 2.392 & $4^{\text {th }}$ vertical \\
$5(\mathrm{~L}-\mathrm{T} 3)$ & 2.797 & $3^{\text {rd }}$ lateral-torsional \\
6 (V5) & 3.632 & $5^{\text {th }}$ vertical \\
7 (T4-L) & 3.668 & $4^{\text {th }}$ torsional-lateral \\
$8(\mathrm{~T} 5-\mathrm{L})$ & 4.744 & $5^{\text {th }}$ torsional-lateral \\
\hline
\end{tabular}

from FE analysis. However, for practical purposes, in total, only eight lowest modes with their associated mode shapes were analysed. Natural frequencies of the identified modes are reported in Table 1 and mode shapes are shown in Figure 6.
The observed modes can be classified as pure bending (V) and coupled torsional-lateral (T-L) or lateral-torsional (L-T) modes of the suspension structure (Table 1). The first lowest natural frequency appears at $0.616 \mathrm{~Hz}$ with a one-node vertical asymmetric bending mode. Note that vertical V1 and torsional T1 symmetric modes with one half waves were not identified. The symmetric mode with one half of the wave cannot exist if the cable is inextensible and supports are fixed (Gimsing, Georgakis 2011). As shown in Figure 6, there are slight lateral vibrations of the system, and a coupling effect between torsional and lateral motion in every mode can be observed. Modes 3, 7 and 8 are dominated by torsional vibration and mode 5 by - lateral vibration. The dominant first horizontal mode shape (frequency $2.797 \mathrm{~Hz}$ ) has significant torsional rotation. The frequency ratio between the first torsional and first vertical modes $\left(f_{T 2} / f_{V 2}=1.812 / 0.616=2.94\right)$ suggests that this type of the bridge has relatively high structural torsional stiffness (Bruno et al. 2011).

\section{Modal parameters of the model for the bridge with the varying rigidity of cables}

Vertical frequencies. The frequencies of all vertical resonant modes of vibration for a different stiffness parameter $\xi$ of the cable are presented in Table 2 and Figure 7. Stiffening effect is clearly observed. It is evident that the natural frequencies of the system are increased with an increment in the bending stiffness of cables (Fig. 7a). a)
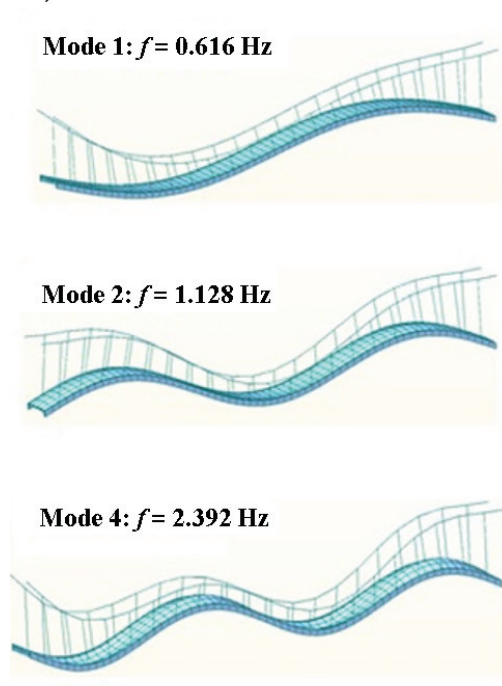

Mode 6: $f=3.632 \mathrm{~Hz}$

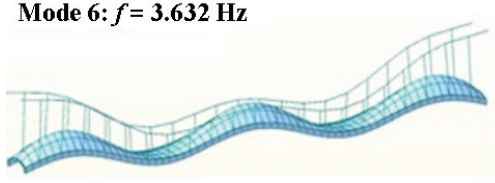

b)
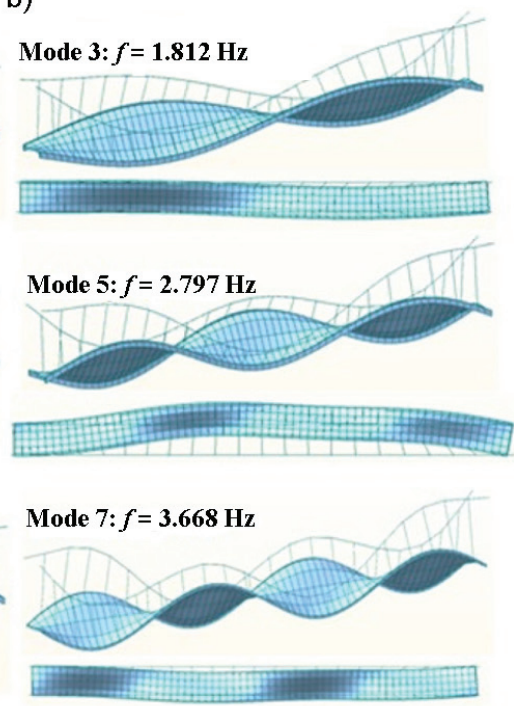

Mode 8: $f=4.744 \mathrm{~Hz}$

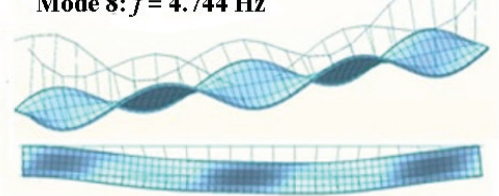

Fig. 6. Mode shapes of the first four vertical (a) and four coupled torsional (b) modes of the model for the bridge 
Table 2. Natural vibration frequencies and the frequency ratio of the first four vertical modes

\begin{tabular}{c|c|c|c|c|c|c|c|c}
\hline$\xi=E I_{c} / E I_{d}$ & $f_{V 2},[\mathrm{~Hz}]$ & $f_{V 2}(\xi) / f_{V 2}(0)$ & $f_{V 3},[\mathrm{~Hz}]$ & $f_{V 3}(\xi) / f_{V 3}(0)$ & $f_{V 4},[\mathrm{~Hz}]$ & $f_{V 4}(\xi) / f_{V 4}(0)$ & $f_{V 5},[\mathrm{~Hz}]$ & $f_{V 5}(\xi) / f_{V 5}(0)$ \\
\hline 0 & 0.616 & 1 & 1.128 & 1 & 2.392 & 1 & 3.632 & 1 \\
0.2 & 0.683 & 1.11 & 1.404 & 1.25 & 2.672 & 1.12 & 4.613 & 1.27 \\
0.5 & 0.695 & 1.13 & 1.433 & 1.27 & 2.720 & 1.14 & 4.685 & 1.29 \\
1.0 & 0.730 & 1.185 & 1.503 & 1.33 & 2.851 & 1.19 & 4.903 & 1.35 \\
2.0 & 0.801 & 1.30 & 1.652 & 1.47 & 3.131 & 1.31 & 5.412 & 1.49 \\
5.0 & 0.982 & 1.60 & 2.031 & 1.80 & 3.824 & 1.60 & 6.538 & 1.80 \\
\hline
\end{tabular}

a)

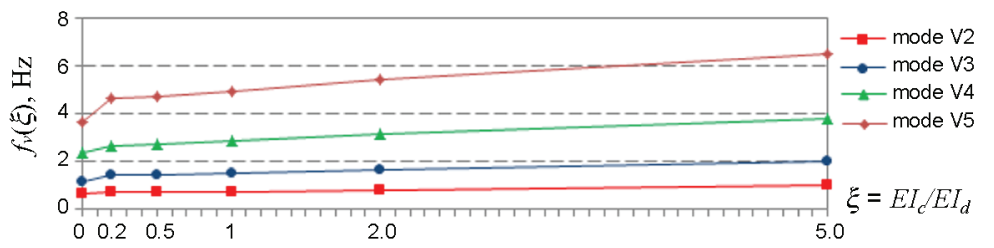

b)

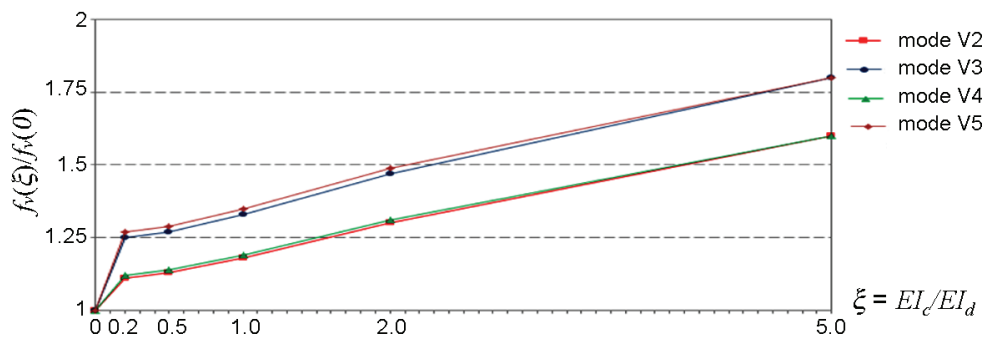

Fig. 7. The effect of the stiffness parameter $\xi$ of the cable on the natural frequencies of vertical modes (a) and the frequency ratio of the system with stiffened cables, $f_{V}(\xi)$ and that of the original system, $f_{V}(0)(\mathrm{b})$

It should be noted that all modes retain the same mode shapes as of the initial system with flexible cables.

Figure 7b shows that, within the range of $\xi$ investigated, the frequency ratio between the frequencies of the system with stiffened cables, $f_{V}(\xi)$, and that of the original system, $f_{V}(0)$, was up to 1.6 times higher for asymmetric modes and up to 1.8 times - for symmetric modes. Higher natural vertical frequencies might be attributed to increase the dynamic stiffness of the whole suspension system. Reordering vibration modes is observed. Modes V4 and V5 that occurred in order 4 and 6 at $\xi=0$, become the fifth and seventh respectively at $\xi=0.2$. Further, mode $\mathrm{V} 5$ changes his position to number 8 at $\xi=2.0$. The second mode V3 in position 2 becomes mode 3 only at $\xi=5.0$.

Torsional frequencies. The frequencies of all torsional resonance modes of vibration for the different stiffness parameter $\xi$ of the cable are presented in Table 3 and Figure 8. First, it can be observed that the effect of cable parameter $\xi$ on torsional frequencies is weaker that on vertical modes (Fig. 8a). It is also evident that cable stiffness has a different effect on torsional natural modes. Figure $8 \mathrm{~b}$ shows that stiffened cables, with respect to those having zero bending stiffness (ratio $f_{T}(\xi) / f_{T}(0)$ ), increase by about 1.25 times only regarding the frequencies of higher modes (T4 and T5) while the first two lower mode frequencies slightly decrease and the rate of reduction is the largest in the first mode T2. It can be assumed, that a decrease might possibly be attributed to the eccentric mass of the cables. This, for instance, in Messina Bridge with a high mass of the cables (Bartoli et al. 2009; Bruno et al. 2011). The contribution of cable stiffness compared to the effect of eccentric masses is small in the lower ranges of $\xi$ and slightly increases with parameter $\xi$. The frequency ratio between the first torsional T2 and first vertical V2 modes $\left(f_{T 2} / f_{V 2}\right)$ gradually decreases from 2.94 at $\xi=0$ to 1.73 at $\xi=5.0$ suggesting that the structural torsional stiffness of the bridge reduces. On the other hand, a reduction in this frequency ratio decreases the risk of the occurrence of flutter instability that is one of the major sources of concern for suspension bridges (Bartoli et al. 2009). Reordering all torsional modes is also observed. Torsional frequencies tend to reduce and, at the same time, vertical frequencies tend to increase influencing the sequence of mode shapes. Changes in the sequence of natural mode shapes are also observed in shallow suspension bridges (Huang et al. 2005). All torsional modes retain the same mode shapes as of the initial system with flexible cables.

Finally, the results of numerical simulation obtained in this section show that the bending stiffness of the cable contributes to a considerable effect on the global natural 
Table 3. Natural vibration frequencies and the frequency ratio of the first four torsional modes

\begin{tabular}{c|c|c|c|c|c|c|c|c}
\hline$\xi=E I_{c} / E I_{d}$ & $f_{T 2},[\mathrm{~Hz}]$ & $f_{T 2}(\xi) / f_{T 2}(0)$ & $f_{T 3},[\mathrm{~Hz}]$ & $f_{T 3}(\xi) / f_{T 3}(0)$ & $f_{T 4},[\mathrm{~Hz}]$ & $f_{T 4}(\xi) / f_{T 4}(0)$ & $f_{T 5},[\mathrm{~Hz}]$ & $f_{T 5}(\xi) / f_{T 5}(0)$ \\
\hline 0 & 1.812 & 1 & 2.797 & 1 & 3.668 & 1 & 4.744 & 1 \\
0.2 & 1.789 & 0.99 & 2.473 & 0.88 & 3.697 & 1.01 & 4.928 & 1.04 \\
0.5 & 1.730 & 0.95 & 2.436 & 0.87 & 3.702 & 1.01 & 5.066 & 1.07 \\
1.0 & 1.690 & 0.93 & 2.443 & 0.87 & 3.728 & 1.02 & 5.175 & 1.09 \\
2.0 & 1.669 & 0.92 & 2.486 & 0.89 & 3.928 & 1.07 & 5.334 & 1.12 \\
5.0 & 1.697 & 0.94 & 2.545 & 0.91 & 4.509 & 1.23 & 5.934 & 1.25 \\
\hline
\end{tabular}

a)

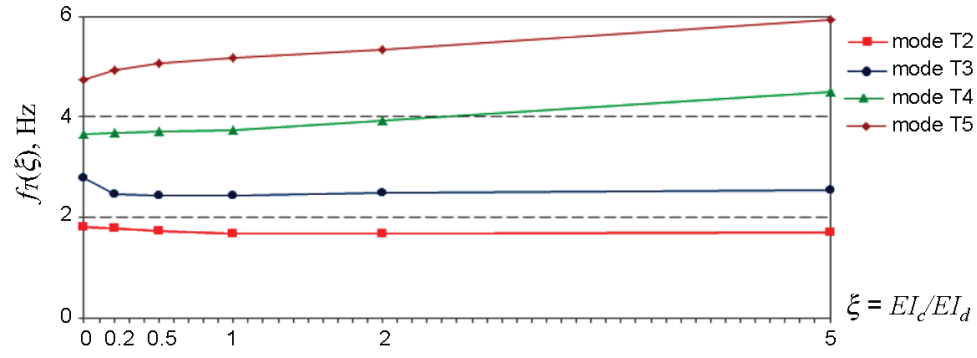

b)

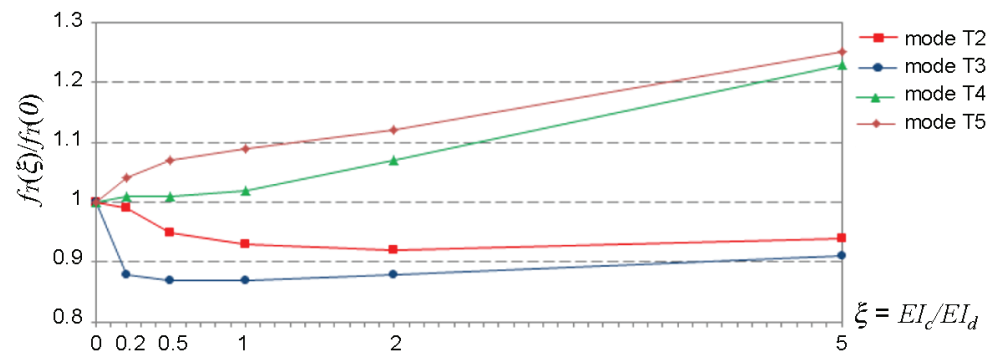

Fig. 8. The effect of the stiffness parameter $\xi$ of the cable on the natural frequencies of torsional modes (a) and the frequency ratio of the system with stiffened cables, $f_{T}(\xi)$, and that of the original system, $f_{T}(0)(\mathrm{b})$

frequencies of the suspension structure. It is interesting to note, that in the simple beam theory, to rise the dynamic bending stiffness of a structure, for example, 1.8 times $(\xi=5.0)$, its stiffness must be increased by a factor of 3.24 without rising mass at the same time. If mass grows, stiffness has to be increased even more. It seems that a strong cable-deck interaction with a dominant role of the stiffened cables exists affecting the global behavior of the suspension structure.

\section{Effect of mass of the cable and the deck}

There are various types and grades of metals and composite materials commonly used for bridge construction. The most sensitive parameters for simulating a finite element model of the suspension bridge to be considered and affecting the modal behavior of suspension systems include geometry and material properties such as elastic modulus ( $E$ and $G$ ) and mass density $(\gamma)$. The effect of geometry and elastic parameters on the stiffness of structural members (cables and stiffening girder) and, as a result, on the global dynamic behavior of the bridge can be observed through the dimensionless stiffness parameter $\xi$ of the cable analysed in the previous section. Variations in the cross sectional area of the cable or the elastic properties of the material lead to variations in parameter $\xi$. This section analyses the effect of the material density of the cable and the girder on the modal behavior of the model for the bridge.

The self-weight effect of the cables and stiffening girder is represented by the relative mass density $\gamma / \gamma_{0}$ of component members where $\gamma_{0}=7850 \mathrm{~kg} / \mathrm{m}^{3}$ is the initial value of steel mass density used in the current model. Numerical simulations of ratio $\gamma / \gamma_{0} 0.25 ; 0.50 ; 0.75 ; 1.0$; 1.25 approximately covering all practical cases were observed.

Main cables. The relationships of frequency $f$-ratio $\gamma / \gamma_{0}$ for the lowest two vertical and two torsional modes were computed considering two values of stiffness parameters $\xi=0$ and $\xi=2.0$ of the cable for comparison and are plotted in Figure 9, which clearly shows that the effect of $\gamma / \gamma_{0}$ on the natural frequencies of the initial system is generally negligible, because the mass of flexible cables for this type of the structure compose only about $3 \%$ of its total mass. However, in the case of $\xi=2.0$, the 


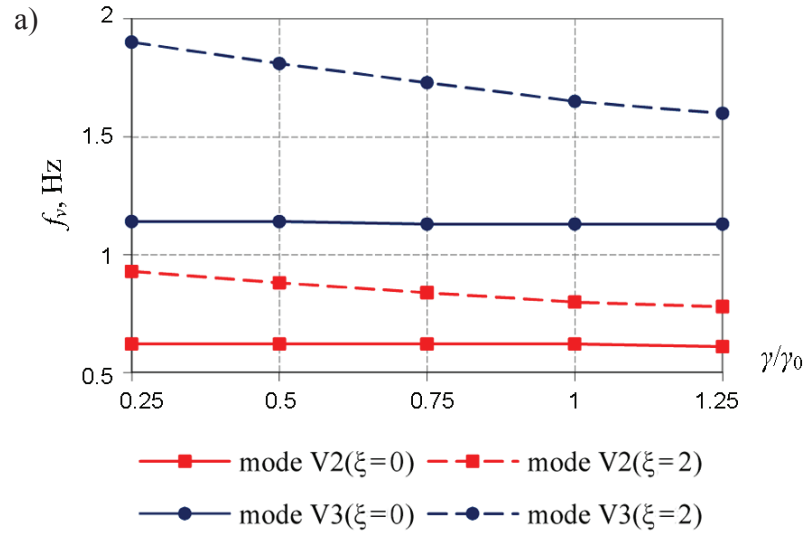

b)

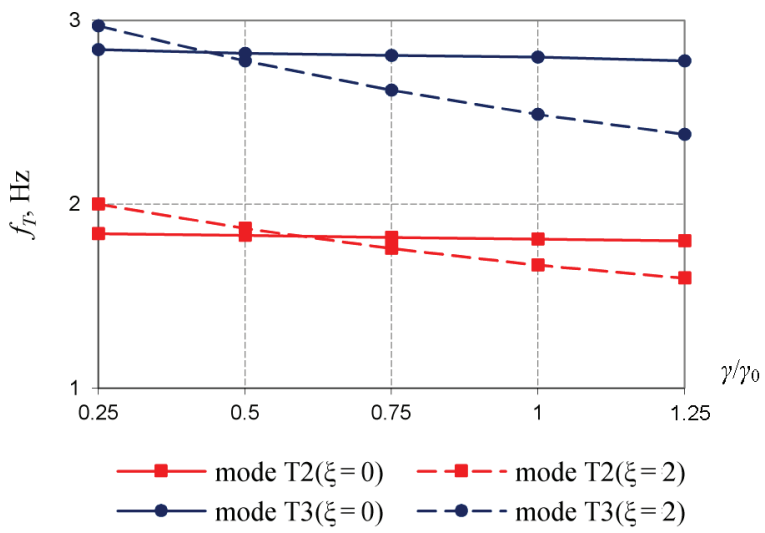

Fig. 9. The effect of the ratio $\gamma / \gamma_{0}$ of the mass density of the cable on the lowest two natural frequencies of vertical (a) and torsional modes (b) considering two values of stiffness parameters $\xi=0$ and $\xi=2.0$ of the cable

tendency for increasing frequencies with a decrease in the mass parameter $\gamma / \gamma_{0}$ of the cable, particularly for its lower values, is observed. The effect of the mass density of the cable can be expressed in terms of frequency ratios $f\left(\gamma / \gamma_{0}\right) / f\left(\gamma / \gamma_{0}=1\right)$, where $f\left(\gamma / \gamma_{0}\right)=1$ is the vertical or torsional frequency of the suspension system made of a traditional steel material. Figure 10 shows that in case of relative mass density $\gamma / \gamma_{0}=0.25$, the value of frequencies can be as high as 1.2.

The effect of rigid cables on the natural vertical and torsional frequencies of the original suspension system is computed as the frequency ratio between the frequencies of the system with stiffened cables $f(\xi)$ and that of the original system $f(0)$ and is plotted in Figure 11. Generally, the frequency ratio increases monotonically with a decrease in ratio $\gamma / \gamma_{0}$. It should be noted that a variation of the self-weight of the cable causes reordering some vertical and torsional modes. Modes V4 and V5 occurred in order 4 and 6 at $\xi=0$, become the fifth and seventh respectively at $\xi=2.0$. Torsional modes $\mathrm{T} 3$ and T4 from positions 5 and 7 at $\xi=0$ have dropped to positions 4 and 6, accordingly.

Stiffening girder. To illustrate the effect of the ratio $\gamma / \gamma_{0}$ of the mass density of the deck on the relative

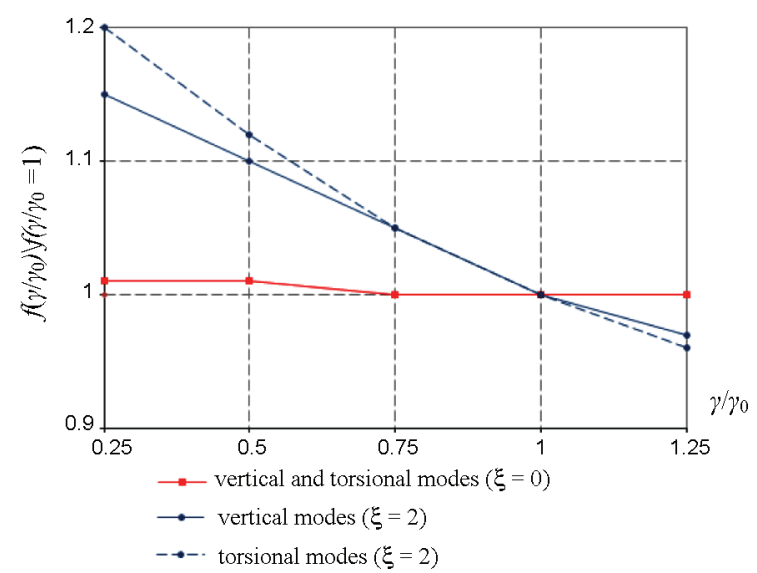

Fig. 10. The ratio between the frequency of the model with the variable mass $f\left(\gamma / \gamma_{0}\right)$ of the cable and that of the original system $f\left(\gamma / \gamma_{0}=1\right)$ for all vertical and torsional modes versus the ratio $\gamma / \gamma_{0}$ of the mass density of the cable considering two values of stiffness parameters $\xi=0$ and $\xi=2.0$ of the cable

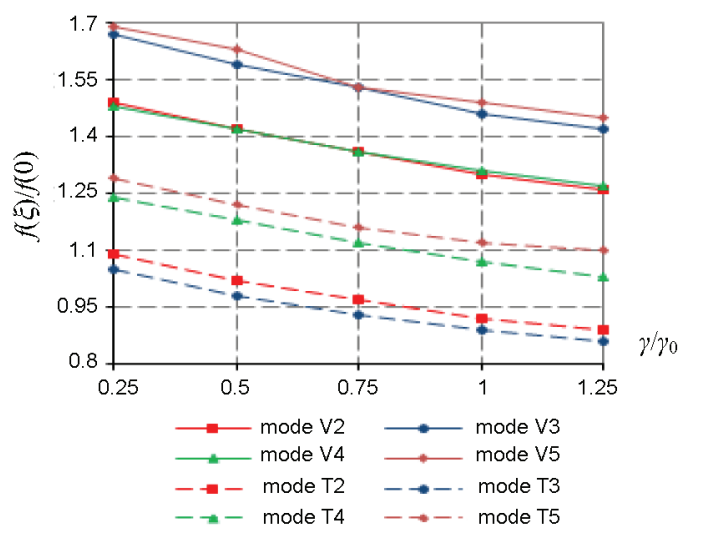

Fig. 11. The ratio between the frequency of the model with stiffened cables $f(\xi)$ and that of the original system $f(0)$ for all vertical and torsional modes versus the ratio $\gamma / \gamma_{0}$ of the mass density of the cable considering the stiffness parameter $\xi=2.0$ of the cable

frequency of the system taking into account two values of stiffness parameters $\xi=0$ and $\xi=2.0$ of the cable, simulation data are plotted in Figure 12. A clear tendency for rising frequencies with decreasing the parameter $\gamma / \gamma_{0}$ of the mass of the deck at an increasing nonlinear rate is observed for both flexible and rigid cable systems. A decrease in ratio $\gamma / \gamma_{0}$ from 1.0 to 0.25 may lead to a $70 \%$ increase in the natural frequency of this type of the structure. As expected, this increase is more significant for the initial system with flexible cables. The influence of $\gamma / \gamma_{0}$ is also stronger on the vertical modes of both systems.

The frequency ratio, $f(\xi) / f(0)$, of all vertical and torsional modes increases with higher $\gamma / \gamma_{0}$ and thus, the selfweight of the deck. The obtained results are shown in Figure 13. A comparison shows that the value of ratio $\gamma / \gamma_{0}$ has a much greater effect on vertical symmetrical modes (V3 and V5) and higher frequency torsional modes (T4 and T5). 


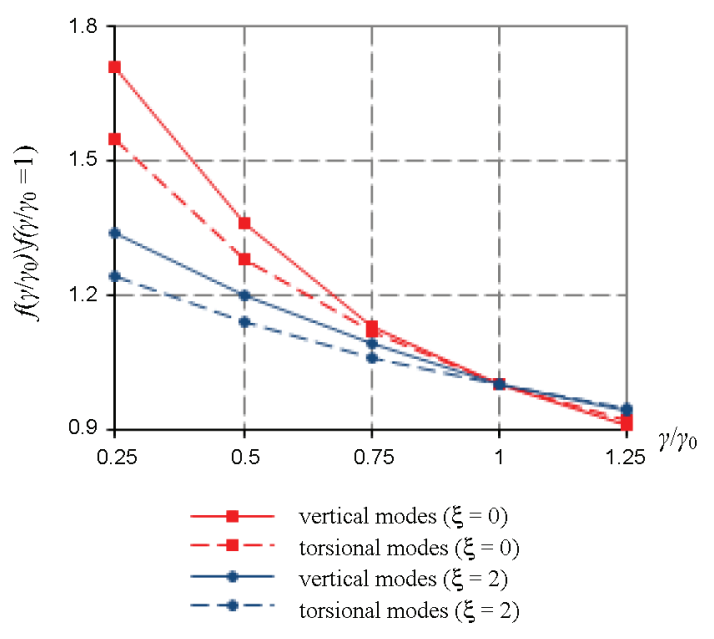

Fig. 12. The ratio between the frequency of the model with the variable mass $f\left(\gamma / \gamma_{0}\right)$ of the deck and that of the original system $f\left(\gamma / \gamma_{0}=1\right)$ for all vertical and torsional modes versus the ratio $\gamma / \gamma_{0}$ of the mass density of the deck considering two values of stiffness parameters $\xi=0$ and $\xi=2.0$ of the cable

Finally, numerical simulation results obtained in this section show that, in certain cases, a decrease in the mass of structures can lead to a favourable effect on the dynamic behaviour of the system because it shifts the resonant frequencies of vertical modes to higher values. This effect is more marked for the bridge deck but becomes less significant for the cable system. It seems, although, that, in some cases, the application of light-weight materials, for example, FRP, comparing to traditional materials, can be reasonable and advantageous.

\section{Analytical natural frequencies}

There are a number of studies based on analytical and experimental work to predict the natural frequencies of typical bridges. Various specifications of bridge design also use similar expressions of calculating fundamental bending frequency with the aim to control structural vibrations. It seems, however, that no specific equations are given as regards the calculation of the flexural fundamental frequency of suspension bridges with stiffened cables that can be used for preliminary design.

A simple expression, based on the simple beam theory about finding period of natural flexural vibrations of the suspension bridges is presented in Gibshman (1969):

$$
T=\frac{2 L^{2}}{i} \sqrt{\frac{m}{g\left(i^{2} \pi^{2} E I+H L^{2}\right)}},
$$

where: $i$ is mode number; $L$ is span length; $g=9.81\left[\mathrm{~m} / \mathrm{s}^{2}\right]$ is acceleration due to gravity; $m$ is self-weight per unit length of the girder; $E I$ is the flexural stiffness of the stiffening girder and $H$ is a horizontal component of cable tension.

On the basis of numerical simulation results presented in this paper, the Eqn (2) was slightly modified adding

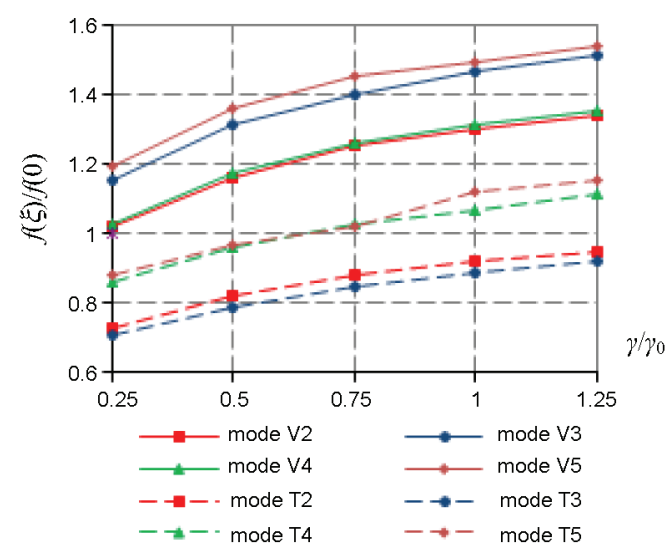

Fig. 13. The ratio between the frequency of the model with stiffened cables $f(\xi)$ and that of the original system $f(0)$ for all vertical and torsional modes versus the ratio $\gamma / \gamma_{0}$ of the mass density of the deck considering the stiffness parameter $\xi=2.0$ of the cable

a correlation term for the bending stiffness of the cable. The proposed equation is as follows:

$$
f_{i}(\xi)=\frac{i}{2 L} \sqrt{\frac{g}{m}\left[\frac{i^{2} \pi^{2}}{L^{2}}+E_{d} I_{d}(1+\xi)+H(\xi)\right]} .
$$

The horizontal component of cable tension $H(\xi)$ is determined from the expression (Grigorjeva et al. 2010):

$$
H(\xi)=\frac{m L^{2}}{8\left(f_{0}+\Delta f_{0}\right)}-\frac{48 E_{c} I_{c} \cdot \Delta f}{5 L^{2}\left(f_{0}+\Delta f_{0}\right)} .
$$

The vertical deflection of the cable at mid-span $\Delta f_{0}$ is given by the expression:

$$
\Delta f_{0}=\frac{0,375 m L^{4}}{16 f_{0}^{2} E A_{c}+28,8 E I_{c}+30 E I_{d}},
$$

where: $m=m_{c}+m_{d}$ is weight per unit length of the cable and deck respectively, $[\mathrm{kN} / \mathrm{m}] ; f_{0}$ is the initial cable sag, [m]; $E A_{c}$ and $E I_{c}$ is tension and the bending stiffness of the cable, $[\mathrm{kN}]$ and $\left[\mathrm{kNm}^{2}\right]$, respectively; $E I_{d}$ is the bending stiffness of the deck, $\left[\mathrm{kNm}^{2}\right]$.

In order to check the validity of the proposed equation, the predicted natural vertical frequencies of the given suspension system were compared with available FEA data. Figure 14 illustrates a comparison between the predicted and experimental frequencies of the varying stiffness of the cable.

In general, the values calculated by Eqn (3) are reasonably close to those determined by FE analysis. The average ratio between the frequencies of the model computed by FEA and those obtained by Eqn (3) for all $x$ values $(0-5.0)$ is 0.970 for mode V2; 0.968 for mode V3; 1.094 for mode V4; 1.209 for mode V5; and 1.039 for mode V6 with a standard deviation of $0.038,0.0764$, $0.0892,0.1241$ and 0.0957 , accordingly. 
a)

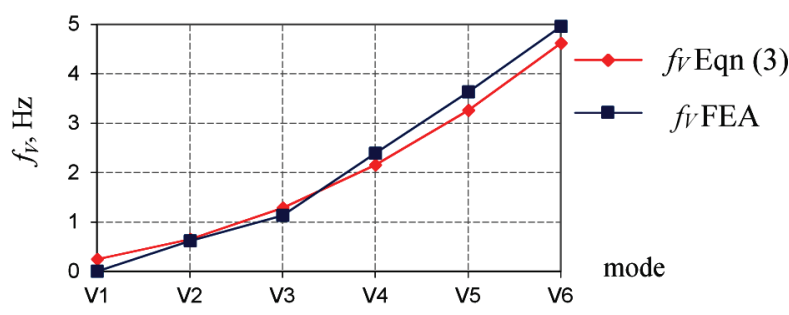

b)

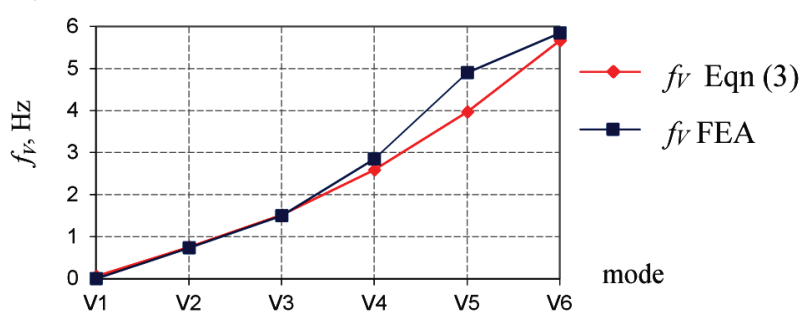

c)

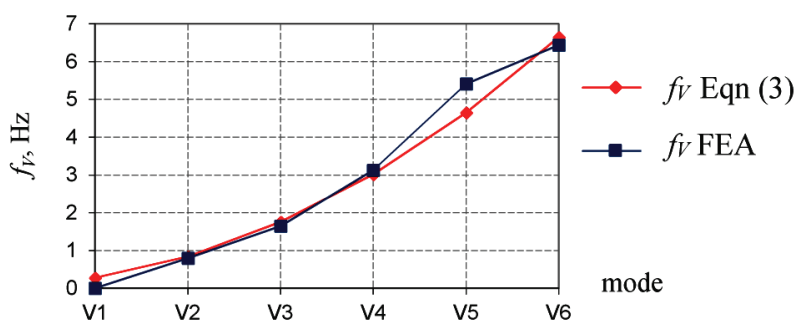

Fig. 14. A comparison between natural frequencies predicted according to Eqn (3) and those obtained by FEA considering stiffness parameters $\xi=0$ (a); $\xi=1.0(\mathrm{~b}) ; \xi=2.0$ (c) of the cable

\section{Conclusions}

A single span steel bridge as a model of a cable suspended structure has been investigated subject to free vibration response. The static nonlinear analysis model developed in program package MIDAS Civil has been used for undertaking a parametric evaluation of the eigen frequency values of the model for the bridge. The first eight lowest natural vibration modes in the range of $0-5 \mathrm{~Hz}$ have been analysed. The investigated parameters included the bending stiffness of the cable, the mass of cables and the bridge deck. Numerical simulations of the given system show that the bending stiffness of the cable contributes to a considerable effect on the natural frequencies of the overall suspension system and affects vertical modes more significantly than torsional ones. The bending stiffness of the cable is also more important for vertical symmetric modes. It is also observed that the first lower frequencies of the torsional modes can slightly decrease when cable stiffness increases, probably, due to a rise in the eccentric mass of cables. The higher stiffness of the cable results in a delay in torsional modes and higher vertical modes leading to reordering vibration modes.
The factor $\gamma / \gamma_{0}$ of the mass density of cables does not make considerable changes in the values of the frequencies of the system with flexible cables. Both vertical and torsional frequencies of the system with rigid cables slightly increase with a reduction in the self-weight of the cable. The effect of the factor $\gamma / \gamma_{0}$ of the mass density of the bridge deck is clearly observed for both flexible and rigid cable systems and the influence on the initial system is stronger. The geometry and material properties of the main cable, including the modulus of elasticity $(E)$ and density $(\gamma)$ values would affect flexural $(E I)$ and torsional $(G J)$ rigidities of cross sections and, as a result, various values of the dynamic stiffness of the whole suspension system.

A simple expression predict in bending natural frequencies of the suspension bridge with the varying bending stiffness of the main cables has been presented for the application as the first step in the design process.

\section{References}

Banerjee, J. R. 2003. A simplified method for the free vibration and flutter analysis of bridge decks, Journal of Sound and Vibration 260(5): 829-845.

http://dx.doi.org/10.1016/S0022-460X(02)00929-X

Barelli, M.; White, J.; Billington, D. P. 2006. History and aesthetics of the Bronx-Whitestone bridge, Journal of Bridge Engineering 11(2): 230-240.

http://dx.doi.org/10.1061/(ASCE)1084-0702(2006)11:2(230)

Bartoli, G.; D’Asdia, P.; Febo, S.; Mannini, C.; Noè, S.; Procino, L. 2009. Innovative configurations for long-span suspension bridges, in Proc. of $5^{\text {th }}$ European and African Conference on Wind Engineering - EACWE 5, 19-23 July 2009, Florence, Italy. 12 p.

Bruno, L.; Venuti, F.; Nasce, V. 2012. Pedestrian-induced torsional vibrations of suspended footbridges: Proposal and evaluations of vibration countermeasures, Engineering Structures 36: 228-238. http://dx.doi.org/10.1016/j.engstruct.2011.12.012

Bruno, L.; Venuti, F.; Scotti, A. 2011. Limit of hanger linearity in suspension footbridge dynamics: a new section model, Journal of Sound and Vibration 330(26): 6387-6406. http://dx.doi.org/10.1016/j.jsv.2011.07.042

Caetano, E. 2007. Cable vibrations in cable-stayed bridges. IABSE Structural engineering documents. Zurich, Switzerland. $188 \mathrm{p}$.

Carpineto, N.; Lacarbonara, W.; Vestroni, F. 2010. Mitigation of pedestrian-induced vibrations in suspension footbridges via multiple tuned mass dampers, Journal of Vibration Control 16(5): 749-776. http://dx.doi.org/10.1177/1077546309350188

El Ouni, M. H.; Kahla, N. B. 2012. Nonlinear dynamic analysis of a cable under first and second order parametric excitations, Journal of Civil Engineering and Management 18(4): 557-567. http://dx.doi.org/10.3846/13923730.2012.702994

Faridani, H. M.; Barghian, M. 2012. Improvement of dynamic performances of suspension footbridges by modifying the hanger systems, Engineering Structures 34: 52-68. http://dx.doi.org/10.1016/j.engstruct.2011.09.025

Geier, R.; De Roeck, G.; Flesch, R. 2006. Accurate cable force determination using ambient vibration measurements, Structure and Infrastructure Engineering 2(1): 43-52. http://dx.doi.org/10.1080/15732470500253123 
Gibshman, E. E. 1969. Proektirovanie metallicheskih mostov [Gibshman, E. E. Design of steel bridges]. Moskva. 416 s.

Gimsing, N. J.; Georgakis, C. T. 2011. Cable supported bridges: concept and design. $3^{\text {th }}$ ed. John Wiley \& Sons. 512 p. http://dx.doi.org/10.1002/9781119978237

Grigorjeva, T.; Juozapaitis, A.; Kamaitis, Z. 2004. Structural analysis of suspension bridges with varying rigidity of main cables, in Proc. of the $8^{\text {th }}$ International Conference "Modern Building Materials, Structures and Techniques", 19-22 May 2004, Vilnius, Lithuania. Selected papers, 469-472.

Grigorjeva, T.; Juozapaitis, A.; Kamaitis, Z. 2008. Finite element modeling for static behavior analysis of suspension bridges with varying rigidity of main cables, The Baltic Journal of Road and Bridge Engineering 3(3): 121-128.

Grigorjeva, T.; Juozapaitis, A.; Kamaitis, Z. 2010. Static analysis and simplified design of suspension bridges with various rigidity of cables, Journal of Civil Engineering and Management 16(3): 363-371. http://dx.doi.org/10.3846/1822-427X.2008.3.121-128

Huang, M.-H.; Thambiratnam, D. P.; Perera, N. J. 2005. Vibration characteristics of shallow suspension bridge with pre-tensioned cables, Engineering Structures 27(8): 12201233. http://dx.doi.org/10.1016/j.engstruct.2005.03.005

Irvin, P. A.; Stoyanoff, S.; Xie, J.; Hunter, M. 2005. Tacoma Narrows 50 years latter - wind engineering investigations for parallel bridges, Bridge Structures 1(1): 3-17. http://dx.doi.org/10.1080/1573248042000274551

Juozapaitis, A.; Idnurm, S.; Kaklauskas, G.; Idnurm, J.; Gribniak, V. 2010. Non-linear analysis of suspension bridges with flexible and rigid cables, Journal of Civil Engineering and Management 16(1): 149-154. http://dx.doi.org/10.3846/jcem.2010.14

Juozapaitis, A.; Kliukas, R.; Sandovič, G.; Lukoševičienė, O.; Merkevičius, T. 2013. Analysis of modern three-span suspension bridges with stiff in bending cables, The Baltic
Journal of Road and Bridge Engineering 8(3): 205-211. http://dx.doi.org/10.3846/bjrbe.2013.26

Luco, J. E.; Turmo, J. 2010. Linear vertical vibrations of suspension bridges: a review of continuum models and some new results, Soil Dynamics and Earthquake Engineering 30(9): 769-781. http://dx.doi.org/10.1016/j.soildyn.2009.10.009

Ni, Y. Q.; Ko, J. M.; Zheng, G. 2002. Dynamic analysis of large-diameter sagged cables taking into account flexural rigidity, Journal of Sound and Vibration 257(2): 301-319. http://dx.doi.org/10.1006/jsvi.2002.5060

Phongkumsing, S.; Wilde, K.; Fujino, Y. 2001. Analytical study on flutter suppression by eccentric mass method on FEM model of long-span suspension bridge, Journal of Wind Engineering and Industrial Aerodynamics 89(6): 515-534. http://dx.doi.org/10.1016/S0167-6105(00)00077-5

Ricciardi, G.; Saitta, F. 2008. A continuous vibration analysis model for cables with sag and bending stiffness, Engineering Structures 30(5): 1459-1472. http://dx.doi.org/10.1016/j.engstruct.2007.08.008

Sousa, R.; Souza, R. M.; Figueiredo, F. P.; Menezes, I. F. 2011. The influence of bending and shear stiffness and rotational inertia in vibration of cables: an analytical approach, Engineering Structures 33(3): 689-695. http://dx.doi.org/10.1016/j.engstruct.2010.11.026

Tabatabai, H.; Mehrabi, A. 2000. Evaluation of various damping treatments for stay cables, in Proc. of Conference of Structural Dynamics - IMAC XVIII, 7-10 February 2000, San Antonio, Texas, USA, 836-841.

Takahashi, K.; Chen, B. 2006. Influence of cable loosening on nonlinear parametric vibrations of inclined cables, Structural Engineering and Mechanics 25(2): 219-237.

Treyssede, F. 2010. Vibration analysis of horizontal self-weighted beams and cables with bending stiffness subject to thermal loads, Journal of Sound and Vibration 329(9): 15361552. http://dx.doi.org/10.1016/j.jsv.2009.11.018

Tatjana GRIGORJEVA. PhD, Assoc Prof at the Dept of Architectural Engineering. Author and co-author of 22 scientific publications. Research interests: bridges, dynamics of bridges, FE analysis.

Zenonas KAMAITIS. Dr Habil, Prof Emeritus at the Dept of Bridges and Special Structures. Member of IABSE since 1999. Author and co-author of more than 180 publications, including 6 books. Research interests: special structures and bridges, materials, durability, monitoring and refurbishment. 